\title{
Obispos de Chile y España en la codificación canónica de 1917: postulata sobre el matrimonio ${ }^{1}$
}

\author{
Carlos Salinas-Araneda \\ FACULTAD DE DERECHO \\ PONTIFICIA UNIVERSIDAD CATÓLICA DE VALPARAÍSO \\ carlos.salinas@pucv.cl
}

Resumen: La redacción del primer Código de Derecho Canónico que tuvo la Iglesia latina fue ordenada por el Papa san Pío X en 1904. La tarea codificadora, empero, no fue obra de un grupo cerrado de expertos, sino que tuvo en cuenta el parecer del episcopado, el que fue consultado en dos momentos diferentes; en ambos fueron consultados los obispos chilenos y españoles. En este trabajo se estudia, a partir de la documentación guardada en el Archivo Secreto Vaticano, el aporte de ambos episcopados en respuesta de la primera consulta, realizada en 1904, en lo referido al matrimonio.

Palabras clave: Derecho canónico, Código de Derecho Canónico de 1917, obispos de Chile, Metropolitanos de España, postulata episcoporum, Matrimonio.

Abstract: The drafting of the first Code of Canon Law of the Latin Catholic Church was ordered by Pope Saint Pius X in 1904. The code was not made by a close group of experts, but considered the opinion of the whole episcopate. Such an opinion was consulted in two different moments. In both, the opinion of Chilean and Spanish bishops was asked. The contribution of both episcopates to the first query in 1904, in reference to marriage is studied in this work. The documentation was obtained from the Vatican Secret Archives.

Keywords: Canon law, Code of Canon Law 1917, Chilean bishops, Spanish Metropolitans, postulata episcoporum, Marriage.

\footnotetext{
Este trabajo forma parte del proyecto de investigación Fondecyt 1160298 del que el autor es investigador responsable. La traducción de la propuesta de los metropolitanos españoles ha sido hecha por los profesores Patricio Serrano Guevara y María Jesús Serrano Loof, de la Facultad de Teología de la Pontificia Universidad Católica de Chile, y revisada por el autor.
} 
Al iniciarse en 1904 las tareas que llevaron a la confección del primer Código de Derecho Canónico que ha tenido la Iglesia, el que se promulgó, hace cien años, por el Papa Benedicto XV (1914-1922)², se hizo una consulta a todo el episcopado latino, ocasión en la que fueron consultados los obispos de Chile y de España, a fin de que expusieran las reformas que consideraban necesario introducir al derecho canónico vigente. Supuestos esos aportes, en las páginas que siguen centro mi atención en las reformas que postularon ambos episcopados en lo referido al matrimonio canónico el que, por entonces, estaba principalmente regulado por los cánones del viejo derecho de las decretales.

Las materias abordadas por los prelados chilenos y españoles en sede matrimonial fueron variadas: esponsales, información matrimonial, supresión o modificación de impedimentos dirimentes - parentesco espiritual, pública honestidad, algunos grados de consanguinidad y de afinidad lícita e ilícita, crimen-, establecimiento de un nuevo impedimento impediente -racionalismo-, diversos aspectos de la dispensa de los impedimentos y de las tasas a cobrar por ello, proclamas matrimoniales, facultades para celebrar matrimonios en circunstancias especiales, matrimonio por sorpresa y divorcio. La sola enunciación de los temas que interesaron a ambos episcopados muestra la variedad de los mismos y la imposibilidad de tratarlos todos siquiera someramente, razón por la que he optado por desarrollar solo algunos de los postulata en una de cada una de las cuatro modalidades que es posible advertir en el tratamiento comparado de los mismos: i) propuestas en que coinciden unos y otros prelados; ii) proposiciones en que ambos episcopados coinciden sustancialmente, pero que presentan peculiaridades en unos y otros; iii) postulata que son originales de los obispos chilenos; iv) sugerencias que son propias de los prelados hispanos.

\section{LA CODIFICACIÓN DEL DERECHO CANÓNICO}

El 31 de julio de 1903, en Roma, entraban en cónclave 62 cardenales que debían elegir al sucesor de León XIII que había fallecido el 20 de ese mismo mes, tras 25 años de pontificado. El 4 de agosto siguiente, 50 de los prelados conclavistas eligieron al cardenal patriarca de Venecia, Giuseppe Melchiorre Sarto, quien asumió el nombre de Pío X. El nuevo

Constitución apostólica Providentissima Mater Ecclesiae, en Acta Apostolicae Sedis 9 (1917) 5-8. 
pontífice no era un jurista, pero a lo largo de su dilatada actividad pastoral, había podido advertir, por una parte, la necesidad del derecho canónico para el gobierno de la Iglesia y, por otra, el defectuoso estado que este presentaba al inicio del nuevo siglo, de lo que ya se habían hecho eco algunos padres conciliares durante el Concilio Vaticano I (18691870). Es por lo que poco después de iniciado su gobierno, el nuevo pontífice acometió la tarea de sustituir el viejo Corpus Iuris Canonici por un moderno Codex Iuris Canonici.

El punto de partida de la empresa codificadora fue el motu proprio "Arduum sane munus", de 19 de marzo de 1904³, mediante el cual creó una comisión pontificia encargada de asumir la codificación del derecho de la Iglesia ${ }^{4}$. El trabajo de esta comisión fue complementado con la intervención de todo el episcopado latino cuya participación fue dispuesta por el mismo motu proprio y se desarrolló en dos etapas: al inicio de los trabajos codificadores, la que dio origen a los postulata episcoporum; y cuando se estaba llegando a la fase conclusiva del proceso codificador, formulando observaciones a los proyectos parciales que les fueron enviados, las que dieron origen a las animadversiones episcoporum. Los obispos, al estar en contacto diario con el gobierno de las iglesias particulares, estaban en condiciones calificadas para poder sugerir las reformas que necesitaba el derecho de la Iglesia, iluminando la tarea de los consultores, con frecuencia hombres más bien teóricos ${ }^{5}$. La respuesta de los obispos fue amplia, contándose entre ellas la de los metropolitanos españoles y de los obispos de la provincia eclesiástica de Chile. En las páginas que siguen me detengo en algunos de los postulata que, en materia de matrimonio, formularon los obispos chilenos y españoles.

\section{La provincia eclesiástica de Chile}

En marzo de 1904 había en Chile un arzobispado -Santiago- y tres obispados sufragáneos -Concepción, San Carlos de Ancud y La Serena-. Arzobispo de Santiago era Mariano Casanova Casanova (1886-1908); obispo de Concepción era Plácido Labarca Olivares (1890-1905); de San Carlos de Ancud era Ramón Ángel Jara Ruz (1898-1909); y de

\footnotetext{
Publicado en Acta Sanctae Sedis 36 (1903-1904) 549-551.

La nómina de sus integrantes en Acta Sanctae Sedis 36 (1903-1904) 551.

A. Vetulani, Codex Juris Canonici, en Dictionnaire de Droit Canonique (Paris, 1942), III, col. 920.
} 
La Serena era Florencio Fontecilla Sánchez (1890-1909). Para auxiliarse en la elaboración de este informe, el arzobispo Casanova nombró una comisión presidida por el obispo titular de Epifanía, Rafael Fernández Concha ${ }^{6}$.

En carta de 14 de junio de 1904 , Ramón Ángel Jara aceptó como propias las observaciones que le merecieren a los miembros de la comisión designada por el arzobispo Casanova, sin perjuicio de lo cual pidió que se le permitiera "llamar la atención [...] hacia los siguientes puntos cuya reforma me atrevería indicar, apoyado en la experiencia del gobierno pastoral". De los diez puntos considerados por él, dos se referían al matrimonio y un tercero hace una referencia general a los sacramentos que, por su misma generalidad, comprendía también al matrimonio.

El obispo de Concepción -Plácido Labarca- respondió al arzobispo de Santiago en carta de 5 de septiembre de $1904^{8}$, incorporando en el texto de la misma tres puntos que sometía al criterio y consideración del arzobispo, uno de los cuales se refería al tema del matrimonio.

El informe del arzobispo Mariano Casanova, conjuntamente con los de Ramón Ángel Jara y Plácido Labarca, fue enviado con una carta escrita en latín, dirigida al cardenal Secretario de Estado, fechada en Santiago el 22 de septiembre de 1904․ El informe del arzobispo Casanova, bajo el título "Información del episcopado chileno sobre las materias que hay que reformar en el derecho canónico según el motu proprio de Nuestro

${ }^{6}$ La integraban los presbíteros Alberto Vial y Carlos Silva Cotapos y los religiosos fray Raimundo Errázuriz, op., y Narciso Sagrega, sj.

7 El original en Archivio Segreto Vaticano, Commissione Cod. Diritto Canonico, scat. 96. Puede verse C. Salinas, "El primer aporte de los obispos chilenos a la codificación del derecho canónico de 1917: los postulata del obispo de Ancud, Ramón Ángel Jara”, en Boletín de la Academia Chilena de la Historia 117 (2008) 161-189.

8 El original en Archivio Segreto... scat. 96. Puede verse C. Salinas, "El primer aporte de los obispos chilenos a la codificación del derecho canónico de 1917: los postulata del obispo de Concepción, Plácido Labarca Olivares”, en Revista de Derecho de la Universidad Católica de la Santísima Concepción 17/1 (2008) 89-105.

$9 \quad$ Su texto en latín se publicó en Boletín Eclesiástico del Arzobispado de Santiago 16 (1904-1907) 154-155 n. 261C, pero no se publicó el texto del informe que se encontraba sub secreto pontificio. El original, junto con el informe, se encuentra en Archivio Segreto..., scat. 96. 
Santísimo Señor el Papa Pío X, De Ecclesiae legibus in unum redigendis" ${ }^{10}$, es un informe extenso, manuscrito en latín en 36 hojas en folio, por un solo lado, cuyo contenido se refiere a diversas materias del derecho canónico vigente, distribuidas en 56 párrafos enumerados con números romanos, que se siguen unos a otros sin mayor individualización ${ }^{11}$.

\section{Los metropolitanos españoles}

$\mathrm{Al}$ momento de iniciarse la codificación canónica, la Iglesia en España estaba organizada en nueve sedes metropolitanas: Burgos ${ }^{12}$, Composte$\mathrm{la}^{13}$, Granada $^{14}$, Zaragoza ${ }^{15}$, Sevilla ${ }^{16}$, Tarragona ${ }^{17}$, Toledo ${ }^{18}$, Valencia ${ }^{19}$ y Valladolid $^{20}$.

Con carta fechada el 20 de julio de $1904^{21}$, el cardenal Ciriaco María Sancha y Hervás, arzobispo de Toledo y patriarca de las Indias Occi-

10 Informatio / episcopatus chilensis de rebus / in Jure Canonico reformandis / juxta motum proprium SSmi. I Dni. Nostri Pii Papae X, del Ecclesiae legibus in unum redigendis /. El subrayado en el original. Archivio Segreto..., scat. 96.

11 Sobre los postulata de los obispos chilenos se puede consultar C. SALInAS, "Los obispos de Chile y la codificación canónica de 1917”, en Teología y Vida 58/3 (2017) 301-337.

12 Sufragáneos: Calahorra y Calzada, León, Osma, Palencia, Santander, Vitoria. Arzobispo de Burgos era Gregorio María Aguirre y García, ofm.

13 Sufragáneos: Lugo, Mondoñedo, Orense, Oviedo, Tuy. Arzobispo de Compostela era el cardenal María Martín de Herrera y de la Iglesia.

14 Sufragáneos: Almería, Cartagena, Guadit, Jaén, Málaga. Arzobispo de Granada era José Moreno y Mazón.

15 Sufragáneos: Barbastro, Huesca, Jaca, Pamplona y Tudela, Tarazona, Teruel. Arzobispo de Zaragoza era Juan Soldevilla y Romero.

16 Sufragáneos: Badajoz, Cádice, Córdoba, Canarias. Arzobispo de Sevilla era Marcelo Spinola y Maestre. Fue beatificado el 29 de marzo de 1987.

17 Sufragáneos: Barcelona, Gerona, Lerida, Solsona, Tortosa, Urgel, Vich. Arzobispo de Tarragona era Tomás Costa y Fornaguera.

18 Sufragáneos: Coria, Cuenca, Madrid-Alcalá, Placencia, Sigüenza. Arzobispo de Toledo era el cardenal Ciriaco María Sancha y Hervás, patriarca de las Indias Occidentales. Fue beatificado el 18 octubre 2009.

19 Sufragáneos: Mallorca e Ibiza, Menorca, Orihuela, Segorbe. El 9 diciembre 1903 había fallecido el arzobispo Sebastián Herrero y Espinosa de los Monteros y su sucesor, Bernardino Nogaleda y Villa, op., fue nombrado el 14 noviembre 1904, cuando el plazo para responder a Roma ya estaba vencido.

20 Sufragáneos: Astorga, Ávila, Ciudad Rodrigo, Salamanca, Segovia, Zamora. Arzobispo de Valladolid era José María Cos y Macho.

21 Archivio Segreto..., scat. 84. 
dentales enviaba a Roma, a nombre de los metropolitanos españoles, en respuesta a la consulta vaticana, las propuestas de reformas que debían introducirse al derecho canónico vigente ${ }^{22}$, las que, al igual que la respuesta chilena, fueron evacuadas en el plazo fijado por Roma. Se trataba de diez páginas impresas - pagellis las llamaba el cardenal- que contenían 56 propuestas, todas ellas numeradas correlativamente, sin subtítulos separadores de las materias abordadas en ellas, y sin que el orden establecido fuera indicador de la mayor o menor importancia que se le daba a cada una de ellas. Seis de los 56 postulata se refirieron al matrimonio a los que me refiero a continuación en paralelo con los postulata sobre el matrimonio arribados a Roma desde Chile.

\section{Propuesta coincidente}

De las diversas propuestas sobre el matrimonio es posible encontrar tan solo una en la que se advierte una total coincidencia: la supresión del impedimento dirimente de parentesco legal. Sería sumamente conveniente, proponían los metropolitanos españoles, de acuerdo a lo que ya había sido requerido en el Concilio Vaticano $\mathrm{I}^{23}$, suprimir el impedimento dirimente de parentesco legal, propuesta que coincidía con la de los obispos de la provincia de Chile que se expresaban en los mismos términos. Para la reducción de este y de los demás impedimentos a los que me referiré más adelante, los arzobispos españoles consideraban preciso tener a la vista, entre otras circunstancias: el enfriamiento de la fe en el tiempo actual, la mala disposición de los abogados para la aplicación de la ley y, simultáneamente, las frecuentes proposiciones de personas maliciosas al matrimonio civil o al concubinato.

La adopción es una institución meramente civil que tiene su origen en el derecho romano en el que alcanzó un notable desarrollo ${ }^{24}$. Como ella generaba un vínculo jurídico -además de afectivo- entre el adoptado y los miembros naturales de la familia del adoptante, los romanos establecieran

22 Archivio Segreto..., scat. 84. En adelante: Postulata.

23 En su propuesta, los obispos españoles hablan solo de "Concilio Vaticano", lo que resulta obvio, pues a la fecha de sus postulata, era el único concilio que se había celebrado en dicho lugar.

24 A. GuZmán, Derecho privado romano (Editorial Jurídica de Chile, Santiago, 1997) I, 360-363. 
prohibiciones para los matrimonios entre unos y otros ${ }^{25}$. La Iglesia aceptó en su propio fuero la legislación romana en relación con este impedimento desde antes del siglo XIII, haciendo canónica-canonificando- dicha legislación. A tenor de esta canonificación ${ }^{26}$, la adopción hecha según las normas de la legislación civil de cada país originaba el impedimento de parentesco legal en el fuero de la Iglesia, pero los matrimonios que se prohibían no eran los prohibidos por el derecho de cada país, sino que los prohibidos por el derecho romano por lo que, para que la adopción prohibiera el matrimonio canónico, era menester que hubiera una conformidad sustancial entre la adopción del país respectivo y la del derecho romano: si dicha conformidad se producía, los matrimonios prohibidos por este impedimento no eran los establecidos en la legislación civil de que se tratase, sino los prohibidos por el derecho romano. De esta manera, la dificultad estribaba en juzgar si la legislación del país acerca de la adopción convenía sustancialmente con la adopción romana ${ }^{27}$. Esta era la disciplina vigente al momento de la codificación.

En lo que a Chile y España se refiere, la adopción estaba regulada sustancialmente en las Siete Partidas, texto del rey Alfonso X el sabio escrito en el siglo XIII que había regido esta materia durante todo el período indiano y que había seguido vigente después de la independencia ${ }^{28}$, texto en el que se había recogido la disciplina del derecho romano. De esta manera, al tiempo de la codificación existía el impedimento canónico ${ }^{29}$ : i) entre el adoptante y el adoptado perpetuamente, porque subsistía la razón de honestidad, aunque no quedase entre ellos la consideración de hijos por la emancipación; ii) entre el adoptado y los hijos legítimos del adoptante mientras duraba la

25 A. GuZMÁn, Derecho..., 338-340.

26 Los canonistas suelen utilizar la palabra canonizar para referirse a la recepción que el derecho canónico hace del derecho estatal. Como dicha expresión tiene en la Iglesia un significado propio, para indicar el acto por el que los beatos son elevados a la calidad de santos, prefiero usar la expresión canonificar.

27 A. Alonso; L. Miguelez; S. Alonso, Comentarios del Código de Derecho Canónico (Madrid, 1963) II, 528.

28 A. GuZmán, Andrés Bello codificador. Historia de la fijación y codificación del derecho civil en Chile (Ediciones de la Universidad de Chile, Santiago, 1982) I, 79-111.

29 J. Donoso, Instituciones de derecho canónico americano (Imprenta y Librería del Mercurio, Valparaíso, 1849) II, 159; P. B. GolmaYo, Instituciones de derecho canónico (Librería de Gabriel Sánchez, Madrid, 7a ed., 1896) II, 29; F. Gómez, Instituciones de derecho canónico (Imprenta de Alejandro Gómez Fuentenebro, Madrid, 2a ed., 1883) III, 232-233; A. MANJón, Derecho eclesiástico general y español (Imprenta de las Escuelas del Ave María, Granada, 3a ed., 1900) II, 238-239; A. DougnaC, Esquema del derecho de familia indiana (Santiago de Chile, 2003)462-480. 
adopción, o sea, mientras la persona adoptada no era emancipada, de modo que si el padre emancipaba a la hija adoptiva, podía esta contraer matrimonio con un hijo legítimo de aquel; iii) entre el adoptante y la mujer del adoptado, y entre este y la mujer de aquél, siendo este impedimento perpetuo como el primero. En cambio, no existía impedimento para el matrimonio entre diversas personas adoptadas por un mismo adoptante.

No fueron solo los obispos chilenos y españoles quienes solicitaron la derogación de este impedimento, pues junto a ellos lo hicieron otros 15 episcopados ${ }^{30}$. Sin embargo, el Código de Derecho Canónico conservó este impedimento, por lo que las propuestas llegadas de Chile y España no fueron acogidas, pero simplificó notablemente la disciplina: "los que por la ley civil son inhábiles para contraer entre sí matrimonio a causa del parentesco legal que nace de la adopción, por prescripción del derecho canónico no pueden casarse entre sí válidamente"31. En cambio, "en los países en donde el parentesco legal que se origina de la adopción, hace por ley civil ilícito el matrimonio, este es también ilícito por derecho canónico"32.

\section{Propuestas Coincidentes EN LO SUSTANCIAL PERO CON PECUliaridAdes PROPIAS}

A diferencia de la única propuesta totalmente coincidente entre las provincias eclesiásticas de Chile y las españolas, más numerosas son aquellas que, siendo similares en lo sustancial, tienen algunas peculiaridades que las diferencian al menos en algunos aspectos. He aquí algunas de ellas.

30 Los padres de las provincias de Poznan, París, Burgos, Bamberg, Guatemala, Lisboa, Montalbán, Montreal, Besançon, Halifax, Lyon, Michoacán, Irlanda y el obispo de Tulle. Codex Iuris Canonici. Postulata Episcoporum in ordinem digesta a Rmo. P. Bernardino Klumper O. F. M. Consultore (Typis Vaticanis, Romae, 1905) 177 [impreso pero no publicado], en ArChivio Segreto..., scat. 4.

31 CIC 1917 can. 1080. Se trató de un caso de canonificación de la ley civil de manera que el impedimento dirimía el matrimonio por disponerlo así el derecho canónico; y como se trataba de un impedimento de derecho eclesiástico era dispensable.

32 CIC 1917 can. 1059. El Código de Derecho Canónico de 1983 conservó también este impedimento, pero a diferencia del código de 1917, unificó la disciplina y definió los grados en que dicho impedimento dirimente se producía: no pueden contraer válidamente matrimonio entre sí quienes están unidos por parentesco legal proveniente de la adopción, en línea recta -ascendientes y descendientes adoptivos- y en segundo grado de línea colateral -hermanos adoptivos- (CIC 1983 can. 1094). 


\section{Esponsales}

Sugería el informe del arzobispo Casanova que, a fin de que se tuvieren como nulos los esponsales que no se habían contraído por escritura pública, había que decretar y declarar esta escritura para que nunca y de ningún modo pudiere ser sustituida por aquellos escritos que, en Chile, se llamaban informaciones matrimoniales o por aquellos por los cuales se pedía una dispensa de impedimentos matrimoniales. Por su parte, los metropolitanos españoles consideraban que era preciso dejar establecido que los esponsales no tendrían ningún valor, a no ser que hubieren sido investidos con todas las solemnidades como en España, pero, incluso, investidos con ellas, que perdieren su valor si no se renovaren anualmente. Siendo coincidentes en lo sustancial, la propuesta española difería en cuanto pedían que los esponsales, para su validez, se renovaren anualmente.

La doctrina definía los esponsales con la fórmula latina "mutua promissio et aceptatio futurarum nuptiarum" 33 , y enumeraba los requisitos para la validez canónica de los mismos, uno de los cuales, que ahora me interesa, era que se manifestasen con palabras u otros signos equivalentes, cumplidos los cuales los esponsales eran válidos y, aunque fueran clandestinos, obligaban en conciencia ${ }^{34}$. Aun cuando se exigía que los esponsales se manifestasen con palabras u otros signos equivalentes, no había prescrita canónicamente ninguna formalidad especial. La ley civil, en cambio, tanto la española como la ley patria chilena, había establecido la exigencia de la escritura pública. En efecto, una pragmática de Carlos III de 28 de abril de $1803^{35}$, disponía que "en ningún tribunal eclesiástico ni secular de mis dominios se admitirán demandas de esponsales, sino es que sean celebrados por personas habilitadas para contraer por sí mismas según los expresados requisitos y practicados por escritura pública”. Esta exigencia legal había sido reconocida por la $S$. Congregación del Concilio el 31 de enero de $1880^{36}$ la que, respondiendo una duda sobre un caso de Placencia ${ }^{37}$, había declarado que "los esponsales

33 J. Donoso, Instituciones..., II, 150.

34 P. B. Golmayo, Instituciones..., II, 39-47; F. Gómez, Instituciones..., III, pp. 174187; A. Manjón, Derecho..., II, 223-235.

35 Recogida en Novísima Recopilación 10, 2, 18. Puede verse G. ViaL, "Aplicación en Chile de la pragmática sobre matrimonio de los hijos de familia", en Revista Chilena de Historia del Derecho 6 (1970) 335-362.

36 Su texto en F. Retamal, Chilensia pontificia (Ediciones Universidad Católica de Chile, Santiago, 2002) II-2, 634-645.

37 A. Manjón, Derecho..., II, 224. 
celebrados en España sin escritura pública, deben ser considerados nulos", la que podía extenderse ante notario público civil o eclesiástico y ante testigos.

Una exigencia similar se hacía en la ley patria chilena dictada para el matrimonio de los menores y conocida como pragmática de matrimonios ${ }^{38}$, en la que se podía leer que "ninguna demanda de esponsales de los que no tienen edad para deliberar por si se admitirá en los tribunales del Estado, si no ha precedido el consentimiento de los padres o personas autorizadas para ello en un instrumento público y fehaciente". El Código Civil (1855), sin embargo, cambió radicalmente la disciplina al disponer que los esponsales "o sea la promesa de matrimonio mutuamente aceptada, es un hecho privado, que las leyes someten enteramente al honor y conciencia del individuo, y que no produce obligación alguna ante la ley civil" ${ }^{39}$.

Aunque el Código Civil chileno negaba todo valor a los esponsales en el fuero secular, ellos seguían existiendo en el fuero canónico, por lo que el arzobispo Casanova en 1894 solicitó a la S. Congregación del Concilio que se extendiera a la arquidiócesis de Santiago la vigencia de la respuesta dada en 1880 para los esponsales celebrados en España ${ }^{40}$. El sínodo del arzobispado de Santiago celebrado por Mariano Casanova al año siguiente, en 1895, sin embargo, nada dijo sobre el particular, salvo alguna norma de carácter general con un fin más bien pedagógico y moralizante, que encargaba a los párrocos y confesores que procuraran "que las mujeres del pueblo sepan que en ningún caso tienen acción ante los jueces civiles para pedir el cumplimiento de la promesa de matrimonio, a fin de evitar en lo posible que por medio de esa promesa se las seduzca para consentir en el pecado" 41 . En cambio, el Concilio Plenario Latinoamericano abordó el tema expresamente, al punto que había parecido a los padres conciliares, quizá inspirados por Casanova, solicitar a León XIII la extensión a América Latina de la declaración que, para España, había dado la S. Congregación del Concilio el 31 de enero de 1880, es decir, pedir que se extendiera para todo el continente, lo que Casanova había pedido para su arquidiócesis, a saber

38 Art. 19 ley de 9 septiembre 1820, pragmática de matrimonios, en Boletín de Leyes (1846) 158-167. C. Salinas, "Algunas consideraciones sobre el matrimonio en la legislación civil de Chile antes del Código Civil (1810-1857)”, en G. E. PInARD; A. Merchan (dir.), Libro homenaje in memoriam Carlos Diaz Rementería (Universidad de Huelva, Huelva, 1998) 644-653.

39 Código Civil de Chile, art. 98 inc. $1^{\circ}$.

40 Su texto en F. Retamal, Chilensia..., II-2, 644-645.

41 Sinodo de Santiago de 1895, art. 1586. 
"los esponsales en nuestras provincias, son inválidos, si no se contraen mediante escritura pública, a cuya escritura no pueden suplir las informaciones matrimoniales, ni las diligencias practicadas en la curia diocesana, o en otra parte, con el fin de obtener la dispensa de algún impedimento, aunque de ellas se infiera la promesa formal de contraer matrimonio".

Esta petición conciliar fue benignamente acogida por el romano pontífice quien, por decreto de la S. Congregación de Asuntos Eclesiásticos Extraordinarios de 1 de enero de $1900^{42}$, concedió la extensión solicitada de la que se dejó expresa constancia en las actas del Concilio ${ }^{43}$. Parece así que fue esta vieja norma española, recogida por el Concilio Plenario Latinoamericano, quizá motivada por el propio arzobispo Casanova, la que inspiró inmediatamente a los obispos chilenos, si bien, ella venía a materializar una práctica que había estado vigente en Chile durante largos años por haberlo dispuesto la ley civil y que ahora estaba vigente en el fuero canónico por la extensión hecha por León XIII.

Los obispos chilenos y españoles no fueron los únicos en solicitar una escritura pública como formalidad especial para los esponsales, pues otros episcopados solicitaron la misma solemnidad ${ }^{44}$. Sin embargo, salvo los metropolitanos españoles, ningún otro episcopado solicitó que, supuesta la escritura pública, los esponsales perdieren su valor si no se renovaren anualmente. Fue una originalidad de los prelados españoles.

El Código de Derecho Canónico, dispuso que la promesa de matrimonio o esponsales, tanto unilateral como bilateral, era nula en ambos fueros "si no se hace por medio de escritura firmada por las partes y además por el párroco u ordinario del lugar, o al menos por dos testigos" ${ }^{45}$. Esto es, dispuso una formalidad expresa para la validez de los esponsales, con lo cual se hacía eco de las peticiones hechas en este sentido; pero no llegó a exigir una escritura pública como lo sugerían los obispos chilenos e hispanos ${ }^{46}$. Nada

\footnotetext{
Su texto en F. Retamal, Chilensia..., II-2, 952-953.

Concilio Plenario de América Latina, 592 n. 1.

Ruan, Lyon y Arras en Francia. Codex Iuris..., 140-141.

CIC 1917, can. $1017 \$ 1$.

46 Los esponsales debían ser por escrito, firmado de puño y letra, escritura que podía hacerse de cuatro formas: i) ante el párroco del lugar; ii) ante el ordinario del lugar; iii) ante solos dos testigos; iv) ante alguno de los anteriores y un testigo más, si alguna de las o ambas no sabían o no podían firmar. A. Alonso; L. Miguelez; S. Alonso, Comentarios..., II, 457.
} 
dijo, en cambio, en relación con la sugerencia hispana de que los esponsales, supuesta la escritura, debieren ser renovados anualmente, por lo que, una vez celebrados, se entendió que seguían vigentes sin necesidad de renovación.

2. Supresión de impedimentos dirimentes

Tanto los prelados chilenos como españoles coincidieron en solicitar la supresión de algunos impedimentos dirimentes, es decir, de aquellos que especificaban algunas circunstancias que, estando presentes en uno o en ambos contrayentes al momento de la emisión del consentimiento sin estar dispensados, acarreaban la nulidad del matrimonio. Pero, si bien coincidían en lo sustancial, presentaban peculiaridades en cada caso. De las diversas propuestas me referiré a dos de ellas.

\section{a) Parentesco espiritual}

Parecía conveniente, decían los obispos chilenos, una madura reflexión sobre la conveniencia de eliminar algunos impedimentos dirimentes, el primero de los cuales era el impedimento de parentesco espiritual. Por su parte, los metropolitanos hispanos entendían que sería sumamente conveniente, de acuerdo a lo que ya había sido requerido en el Concilio Vaticano I, suprimir diversos impedimentos dirimentes, entre los que se contaba el impedimento de parentesco espiritual, con excepción del que se originaba entre el padrino y el bautizado; es decir, proponían más bien la reducción del mismo que su supresión.

El parentesco espiritual, como sucedió con otros impedimentos, fue más antiguo que su positivación como impedimento, introduciéndose por la costumbre y por algunas disposiciones legislativas particulares hasta que alcanzó carácter universal. De hecho, en el derecho de las Decretales se resuelven algunas dudas que suponen la vigencia del impedimento ${ }^{47}$, el que, por la variedad de situaciones que lo configuraban, suscitaba problemas, los que se veían agravados por la multiplicidad de padrinos. El fundamento de este impedimento fue la regeneración o nueva vida que se daba por el bautismo y la confirmación, de manera que el bautizante y el padrino se consideraban como padres del regenerado. La doctrina de que el parentesco espiritual era mayor que el procedente de la unión carnal, dio lugar a que este impedimento se llevase a un grado de exageración poco conveniente ${ }^{48}$,

\footnotetext{
X, 4, 11: 1, 2, 3; in VI 4, 3.

48 P. B. Golmayo, Instituciones..., II, 30-31.
} 
hasta que el Concilio de Trento ${ }^{49}$ fijó la disciplina vigente al tiempo de la codificación: un solo padrino -vel ad summum unus et una- y redujo la figura del impedimento a la paternidad espiritual, esto es entre bautizante y bautizado y entre padrinos y bautizado, y a la compaternidad, o sea, entre los padres del bautizado y el bautizante y padrinos. En el sentir común, este impedimento comprendía también al que, en caso de necesidad, confería el bautismo privado, aceptándose, empero, algunas excepciones ${ }^{50}$. Se trataba de un impedimento de derecho eclesiástico y, por lo mismo, dispensable.

Puesto que se trataba de una materia definida por el derecho universal, nada dijeron sobre el particular ni el sínodo santiaguino de 1895 ni el Concilio Plenario Latinoamericano, pero ya en el Concilio Vaticano I (1860-1870) se había sugerido modificar este impedimento restringiéndolo al bautizado y padrinos y derogando lo referido al sacramento de la confirmación ${ }^{51}$, que era lo propuesto por los prelados españoles, a diferencia de los chilenos cuya propuesta era más avanzada en su contenido, pues se trataba de suprimir sin más el impedimento. Participaron de la misma opinión chilena diversos episcopados que sugirieron la eliminación de este impedimento tanto en el impedimento originado por el bautismo como por la confirmación ${ }^{52}$.

El Código de Derecho Canónico no eliminó el impedimento, pero, recogiendo lo que ya se había sugerido en el Concilio Vaticano I, repetido por los prelados españoles, lo limitó estableciendo que "solamente el bautizante y el padrino contraen por el bautismo parentesco espiritual con el bautizado" 53 . Se trataba, además, de un impedimento de grado menor, por lo que la dispensa del mismo se concedía con facilidad ${ }^{54}$.

49 Conc. Trid. sess. 24 c. 2 de ref. mat.

50 J. Donoso, Instituciones..., II, 23-24, como el caso del padre que bautiza a su hijo en caso de necesidad, el que no se ve obligado a separarse de su cónyuge.

51 M. CONTE, Institutiones iuris canonici ad usum utriusque clero et scholarum. De sacramentis tractatus canonicus, III: De matrimonio et de sacramentalibus (3ed., Torino, 1957) 558.

52 El arzobispo de Alger y trece episcopados más. Codex Iuris..., 162.

53 CIC 1917 cann. 768, 1079.

54 J. De Salazar, "Capacidad e impedimentos matrimoniales", en Catedráticos de DERECho CANÓNICO DE UniVERSIDAdes españolas, Derecho canónico (Eunsa, Pamplona, 1977) 428. Hubo que esperar hasta el Código de Derecho Canónico de 1983 para que la sugerencia de los obispos chilenos fuera finalmente acogida y se eliminase el impedimento de parentesco espiritual. 


\section{b) Pública honestidad}

Los obispos chilenos sugerían derechamente una madura reflexión sobre la conveniencia de su eliminación. Los arzobispos españoles, en cambio, solo sugerían la supresión de este impedimento cuando era originado por los esponsales celebrados; y en el segundo grado cuando era originado en matrimonio válido ${ }^{55}$.

Golmayo $^{56}$ definía la pública honestidad o cuasi afinidad como "el parentesco que proviene de los esponsales y el matrimonio rato" 57 y tenía lugar cuando se disolvía "alguno de estos actos", de manera que las personas que los habían contraído no podían casarse con los consanguíneos de la otra, hasta el cuarto grado si había habido matrimonio, y el primero si era por razón de esponsales válidos. Era un impedimento de derecho eclesiástico y, por ello, dispensable. Antes del Concilio de Trento (1545-1563), el impedimento se extendía hasta el cuarto grado ${ }^{58}$, ya naciese de los esponsales o del matrimonio rato, aun cuando uno y otro fueran inválidos. El tridentino ${ }^{59}$ varió esa doctrina en lo que se refería a los esponsales, de manera que el impedimento proveniente de esta causa se extendió solo a la hermana, madre o hija de la mujer y viceversa. En cambio, no varió la disciplina del impedimento cuando su origen era un matrimonio rato. En lo que se refería al impedimento nacido de esponsales, el impedimento permanecía aun después de disueltos aquellos, ya se disolvieren por la muerte, por mutuo consentimiento o por otra causa legal. Disputaban los autores si nacía el impedimento solo de los

55 Contado al modo canónico, de manera que el impedimento quedaba restringido al esposo supérstite con la madre, abuela, tías e hijas de la esposa difunta y viceversa; lo que tenía lugar aun cuando el matrimonio rato hubiese sido declarado nulo.

56 P. B. Golmayo, Instituciones..., II, 31.

57 Más preciso era Donoso que la consideraba una "especie de parentesco". J. Donoso, Instituciones... II, 163-164.

58 Contados a la manera canónica y no a la manera romana, o sea hasta el octavo grado colateral romano - primos en tercer grado- o cuarto en línea recta -tatarabuelo, tataranieto-. Desde el siglo IX la Iglesia adoptó la modalidad germánica de contar el parentesco, que solo tenía en cuenta el número de generaciones existente en la línea más larga. Código de Derecho Canónico [1917], can. 96. La modalidad romana, que es la que recibe el Código Civil chileno y español es la que adopta el actual Código de Derecho Canónico [1983], can. 108.

59 Conc. Trid. sess. 24 c. 3 de ref. mat. 
esponsales públicos, celebrados con las solemnidades legales, o también de los privados y ocultos ${ }^{60}$.

Otros nueve episcopados coincidían con la propuesta chilena ${ }^{61}$; y no fueron pocos los que sugirieron la supresión del impedimento a causa de los esponsales, como proponían los prelados hispanos ${ }^{62}$. El código no aceptó el planteamiento de los obispos chilenos en orden a eliminar este impedimento, pues lo conservó; pero cambió su regulación respecto del derecho anterior, pues, en la nueva configuración el impedimento se originó solo del matrimonio inválido, consumado o no, y del concubinato público o notorio, con lo que acogió la propuesta española de eliminar este impedimento cuando se originaba en los esponsales. Y dirimió el matrimonio en primero y segundo grado de línea recta entre el varón y las consanguíneas de la mujer y viceversa ${ }^{63}$, grados contados a la manera canónica, por lo que se prohibía el matrimonio entre el varón y la madre, abuela e hijas o nietas de la mujer y viceversa; es decir, en esta parte del impedimento no fue acogida la pretensión hispana ${ }^{64}$.

\section{Propuestas SOlO de los Obispos Chilenos}

\section{Racionalismo como impedimento impediente}

El informe enviado por el arzobispo Casanova incluyó la novedad de sugerir que el racionalismo fuese considerado un impedimento impediente; es decir, que estuviese prohibido el matrimonio con personas que profesasen dichas ideas, de manera de verse obligadas, antes de celebrar matrimonio, a pedir la respectiva dispensa. Es posible que las tensiones originadas por las corrientes ideológicas beligerantes con la Iglesia que habían ido desarrollándose en Chile, especialmente durante la segunda mitad del siglo XIX,

60 P. B. Golmayo, Instituciones..., II, 31.

61 La región subalpina, Aprutio, Rhemen, Albi, Baltimore, Irentone, Escocia, Burgos y Bourges. Codex Iuris..., 175.

62 París y otros 25 episcopados. Codex Iuris..., 166.

63 CIC 1917 can. 1078.

64 El Código de 1983 igualmente lo conservó, restringiendo aún más el ámbito del mismo al dirimir el matrimonio en el primer grado de línea recta entre el varón y las consanguíneas de la mujer y viceversa (can. 1093), grados que ahora se cuentan al modo romano (can. 108), o sea, entre el varón y la madre o hijas de su cónyuge y entre esta y el padre o hijos del marido, y surge del matrimonio inválido después de instaurada la vida en común, o del concubinato notorio o público. 
estuvieran en la base de esta propuesta. No hubo en los postulata españoles una sugerencia similar.

Los impedimentos matrimoniales impedientes eran "los que sin invalidarlo, impiden su lícita celebración" ${ }^{65}$ y, al tiempo de la codificación, se recogían en el verso "Ecclesiae vetitum, tempus, sponsalia, votum", que servían para recordar los más importantes, pero no para expresarlos todos ni para determinarlos ${ }^{66}$. Por su parte, la facultad de establecer nuevos impedimentos, dirimentes o impedientes, correspondía solo a la autoridad suprema de la Iglesia, esto es, el concilio general o el romano pontífice; y aunque en sentir de muchos teólogos correspondía también esta facultad a los obispos, "es menester confesar que este es un asunto reservado, hoy día, exclusivamente al concilio general y a la Silla Apostólica” ${ }^{67}$.

Solo el informe del arzobispo Casanova hizo una sugerencia de esta naturaleza, la que, en los términos en que fue presentada, no tuvo mayor suceso porque el código nada dijo sobre el racionalismo en particular. Pero la ratio legis de la sugerencia chilena fue recogida en términos más generales por el código al disponer: "apártese igualmente a los fieles de contraer matrimonio con aquellos que notoriamente abandonaron la fe católica, aunque no estén afiliados a una secta acatólica, o con los que dieron su nombre a asociaciones condenadas por la Iglesia" 68 . Así, no solo el postulatum chileno quedaba de lleno incluido en dicho canon, sino que, además, permitía la inclusión de otras figuras en las que los prelados chilenos quizá no habían pensado.

2. Dispensa de impedimentos matrimoniales de derecho eclesiástico en casos de urgencia

El obispo chileno de Concepción, Plácido Labarca, propuso que los curas pudieren dispensar impedimentos matrimoniales de derecho eclesiástico, en casos de verdadera urgencia, en que era difícil y tardío el recurso al prelado. Según la doctrina de la época ${ }^{69}$, era constante en el derecho que el romano pontífice, en su carácter de jefe supremo de la Iglesia, pudiese dispensar en todos los impedimentos que dirimían el matrimonio por derecho eclesiástico. Los obispos, en cambio, por derecho común, no podían dispen-

\footnotetext{
65 J. Donoso, Instituciones..., II, 154.

66 J. Donoso, Instituciones..., 171; P. B. Golmayo, Instituciones..., II, 36; A. ManJÓN, Derecho..., II, 229; F. GÓMEZ, Instituciones..., III, 223.

67 J. Donoso, Instituciones..., II, 155.

68 CIC 1917, can. $1065 \$ 1$.

69 J. Donoso, Instituciones..., II, 186-187; F. GÓMEZ, Instituciones..., 247-249.
} 
sar de ningún impedimento dirimente, aun cuando los obispos de América Latina podían dispensar de varios de ellos en virtud de las sólitas ${ }^{70}$; posibilidad que se ampliaba con las facultades que se solían delegar especialmente en ellos ${ }^{71}$. Los párrocos, por su parte, no podían dispensar a sus feligreses "en las leyes y preceptos eclesiásticos, porque esa facultad corresponde a la jurisdicción voluntaria en el fuero externo, de que carecen los párrocos"72.

Las facultades de dispensar impedimentos matrimoniales con que contaban los obispos en general, y los de América Latina en particular, se limitaban solo a algunos impedimentos y solo en situaciones normales en las que, disponiendo del tiempo necesario, se podían hacer las preces para solicitar la respectiva dispensa. Durante los tres siglos anteriores, sin embargo, los canonistas habían hablado de epiqueya o de licencia presunta para dispensar en ciertos y determinados casos de suma urgencia ${ }^{73}$. Esta doctrina fue recogida por León XIII en un decreto de 20 de febrero de $1888^{74}$, por el cual concedió a los obispos facultades amplias para dispensar a los enfermos en gravísimo peligro de muerte, cuando no era posible recurrir a la Santa Sede, de todos los impedimentos, excepto los que procedían del sagrado orden del presbiterado y de la afinidad en línea recta con consumación del matrimonio. De

$70 \quad 1^{\circ}$ en el tercer y cuarto grado así de consanguinidad como de afinidad, y aún en el tercero mixto con segundo, esto es tío y sobrino hijo de un primo hermano; y tratándose de matrimonio ya celebrado, aún en el segundo grado puro esto es primos hermanos, pero solo respecto de los que se convierten al catolicismo de la herejía o de la infidelidad. $2^{\circ}$ en el impedimento de pública honestidad proveniente de esponsales válidos. $3^{\circ}$ en el impedimento de crimen, neutro tamen conjugum machinante; $4^{\circ}$ en el impedimento de parentesco espiritual praeter quam inter levantem et levantum. Las sólitas eran las facultades que la Santa Sede delegaba habitualmente en los obispos americanos en razón de la lejanía con Roma.

71 Dispensar en segundo grado de consanguinidad mixto con primero y en el primero de afinidad en línea colateral, además de que generalmente se concedía en todo impedimento que solía ser dispensado por la Silla Apostólica.

72 J. Donoso, Instituciones..., I, 246.

73 A. Alonso; L. Miguelez; S. Alonso, Comentarios...., II, 496.

74 Litt. encycl. de la S. Congregación del Santo Oficio, de 20 febrero 1888, en Acta Sanctae Sedis 20 (1887) 543-544. 
estos decretos fueron concediéndose ampliaciones sucesivas por León XIII ${ }^{75}$ y por Pío $\mathrm{X}^{76}$.

La propuesta del obispo de Concepción significaba una innovación importante al solicitar que se concediese a los curas unas facultades que solo desde tiempos muy recientes habían empezado a concederse a los obispos. Coincidían con él los padres de la provincia de Pondycherry que pedían la misma facultad para todos los sacerdotes ${ }^{77}$.

La disciplina innovadora de León XIII y Pío X fue recogida por el código con notables ampliaciones en los cánones 1043-1045. De acuerdo con el primero de dichos cánones, en peligro de muerte, para atender a la conciencia y, si el caso lo pedía, a la legitimación de la prole, podían los ordinarios locales dispensar a sus súbditos, dondequiera que residiesen, y a todos los demás que se hallasen dentro de su territorio, no solo de observar la forma prescrita para la celebración del matrimonio, sino también de todos y cada uno de los impedimentos de derecho eclesiástico tanto públicos como ocultos, y aun múltiples, exceptuados los que procedían del sagrado orden del presbiterado y de la afinidad en línea recta con consumación del matrimonio, evitando el escándalo y, si se concedía dispensa del impedimento de disparidad de cultos o de mixta religión, una vez que se hubiesen dado las garantías de costumbre. En estas mismas circunstancias, establecía el canon 1044, y solamente en aquellos casos en que ni aun se pudiese acudir al ordinario del lugar, gozaban de igual facultad de dispensar tanto el párroco como el sacerdote que asistía al casamiento, y el confesor, si bien este solo en el acto de la confesión sacramental y para el fuero interno. También los ordinarios locales, según el canon 1045, ante situaciones de caso perplejo, esto es, cuando el impedimento se descubría estando ya todo preparado para el casamiento y este no podía deferirse sin peligro probable de un mal grave hasta que se obtuviese de la Santa Sede la dispensa, podían conceder dispensa de todos los impedimentos antes referidos, facultad que se extendía también al sacerdote que asistía al matrimonio y al confesor en el acto de la confesión sacramental y para el fuero interno. De esta manera, la petición del obispo de Concepción quedaba ampliamente recogida en la nueva codificación.

75 Litt. Encycl. de la S. Congregación del Santo Oficio, de 1 marzo 1889, en Acta Sanctae Sedis 21 (1888) 696; de 23 abril 1890, en Acta Sanctae Sedis 26 (18931894) 385-387; de 13 diciembre 1899, Acta Sanctae Sedis32 (1899-1900) 500-501.

76 Decreto de la S. Congregación de Sacramentos, de 14 mayo 1909, en Acta Apostolicae Sedis 1 (1909)468-469.

77 Codex Iuris..., 154. 


\section{Propuestas solo de los metropolitanos españoles}

Tal como había sucedido con los obispos chilenos, hubo entre las propuestas de los metropolitanos españoles, algunas que solo fueron sugeridas por ellos, sin que hubiera coincidencia, en lo referido a ellas, con los obispos chilenos.

\section{Supresión de los matrimonios por sorpresa}

"Por causa del defecto de fe en el pueblo cristiano, la corrupción de las costumbres y la excesiva permisividad en estos tiempos calamitosos", escribían los metropolitanos españoles ${ }^{78}$, habían aparecido muchos matrimonios infelices denominados por sorpresa, matrimonios que no eran queridos ni por el propio párroco ni por el ordinario, "antes bien [eran] contraídos de forma repugnante". Esto ocurría porque eran muchos los que padecían de una gran ignorancia religiosa, pero que astutamente y contra lo que sabían, "habían abierto sus ojos al mal". Para precaverse de tales y tantos males y escándalos perturbadores del orden, proponían los metropolitanos españoles que los matrimonios celebrados bajo tales circunstancias debían declararse nulos. Los obispos chilenos no se pronunciaron sobre esta corruptela.

El triunfo del consensualismo en materia matrimonial se produjo como consecuencia de la reflexión medieval llevada adelante por los canonistas en la época del ius commune quienes sentaron el principio que "consensus facit nuptias non concubitus", lo que hace el matrimonio es el consentimiento no el concúbito. Pero los canonistas se limitaron a afirmar el principio sin especificar la forma en que dicho consentimiento debía prestarse, lo que vino a establecerse en el Concilio de Trento ${ }^{79}$ en el que se estableció una forma especial para emitir el consentimiento matrimonial, forma sin la cual el matrimonio era inválido, y que consistía en la presencia de un testigo cualificado, el párroco de uno o de ambos contrayentes que recibía el consentimiento conyugal en nombre de la Iglesia, y dos o tres testigos comunes. Pero el concilio nada dijo en cuanto a la forma como debía actuar el párroco al momento de recibir el consentimiento conyugal, lo que dio origen a la corruptela de los matrimonios por sorpresa: hubo ocasiones en que los contrayentes sorprendían

\footnotetext{
Postulata no 47. Archivio Segreto... scat. 84.

79 Conc. Trid. sess. 24 c. 1 de ref. mat.
} 
al párroco desprevenido y emitían delante de él y de testigos comunes un consentimiento que, en circunstancias ordinarias, el párroco no habría aceptado recibir. Por algún tiempo se dudó si estos matrimonios eran válidos o no, pues quienes entendían que el párroco era el ministro del sacramento del matrimonio, siguiendo la doctrina de Melchor Cano, negaban validez a los matrimonios contraídos por sorpresa. Sin embargo, las declaraciones de las Sagradas Congregaciones quitaron toda duda acerca de la validez de estos matrimonios, si bien eran ilícitos ${ }^{80}$.

El problema no dio origen a simples episodios aislados, al punto que la literatura se hizo eco de ellos ${ }^{81}$, por lo que la Iglesia debió una vez más arbitrar una solución, la que vino una vez iniciado el proceso codificador, con el decreto Ne temere, de Pío X, de 2 de agosto de 1907, cuya entrada en vigencia se produjo el 19 de abril del año siguiente ${ }^{82}$ en el que dispuso que, para la válida actuación del sacerdote durante la celebración matrimonial, debía él pedir el consentimiento, no siendo suficiente, para la validez, su sola presencia pasiva. De esta forma, la solución a este problema se había producido diez años antes de la promulgación del Codex, el que se limitó a recogerla en el canon 1095, según el cual "el párroco o el ordinario local asisten válidamente al matrimonio: $3^{\circ}$ con tal que pidan y reciban el consentimiento de los contrayentes, sin que a ello sean compelidos por fuerza o miedo grave".

\section{Divorcio no vincular}

Convenía determinar taxativamente, escribían los prelados españoles ${ }^{83}$, el número y la índole de las causas que podrían dar lugar al divorcio, tanto temporal como perpetuo; y puesto que frecuentemente ocurría que el divorcio semipleno perpetuo se pedía a causa del adulterio, que no se probaba con posterioridad aunque resultaba que el acusado había procedido con menor rectitud, convenía establecer que la inmoralidad manifiesta fuere causa suficiente para determinar el divorcio temporal. Sobre esta materia, los obispos de Chile guardaron silencio.

\footnotetext{
80 F. GÓMEZ; V. DE LA FuENTE, Lecciones de disciplina eclesiástica y suplemento al tratado teórico-práctico de procedimientos eclesiásticos (Imprenta de Alejandro Gómez Fuentenebro, $3^{\text {a }}$ ed., Madrid, 1880), II, 259.

81 Por ejemplo, la novela Los novios, de Alejandro Manzoni.

82 Acta Sanctae Sedis 40 (1907)525-530.

83 Postulata no 48. Archivio Segreto... scat. 84
} 
En un conocido manual de derecho canónico español de la época ${ }^{84}$ se definía el divorcio como "la separación de los cónyuges en cuanto al lecho y habitación”, definición de la que se desprendía que los cónyuges quedaban exentos de la obligación "de unirse entre sí carnalmente" y de vivir juntos, lo que se expresaba con las palabras "quoad thorum" y "quoad habitationem". El divorcio podía ser perpetuo o temporal, según que se declaraba por tiempo limitado o para siempre, especies, ambas, a las que se referían los arzobispos hispanos.

El divorcio, sin embargo, no podía decretarse por cualquier causa, por lo que era necesario "un motivo poderoso" ${ }^{55}$ que así lo aconsejare, porque se trataba de un asunto de "trascendentales consecuencias y grave por su naturaleza" ${ }^{\prime 6}$. Dichas causas, empero, estaban consignadas separadamente en diversos textos canónicos, sin que todas ellas estuvieran sistematizadas, que era lo que solicitaban los metropolitanos. Se trataba de uno de los problemas principales que presentaba el derecho canónico vigente por lo que, no solo en esta, sino en otras materias, tanto los arzobispos hispanos ${ }^{87}$ como los obispos de la provincia chilena ${ }^{88}$ sugirieron una labor similar por parte de los codificadores. Era, por lo demás, una de la tantas operaciones codificadoras que, sobre el derecho vigente, debieron llevar adelante los codificadores de uno y otro derecho al tiempo de la confección de los códigos ${ }^{89}$. Habían sido los autores ${ }^{90}$ quienes, en sus textos, habían sistematizado estas causas con más o menos detalle.

84 F. GÓMEZ, Instituciones..., III, 253.

85 F. GÓMEZ, Instituciones..., III, 253.

86 F. GÓmeZ, Instituciones..., III, 253.

87 Por ejemplo, postularon que se reuniese en una sección especial todo aquello que, concerniendo a los delitos y las penas de los regulares, se encuentra esparcido en distintos lugares del Corpus Iuris Canonici (LII), así como que se enumerare taxativamente y con mucha precisión, en un orden que no ofreciere dudas, los casos en que un ministro cometía delito (LVI).

88 Por ejemplo, respecto de los terciarios, les parecía conveniente recoger en el nuevo código todo lo que acerca de esta materia estuviere vigente (XLV); algo similar sugerían a propósito de las indulgencias, de manera que se les asignara un título peculiar en el que, en reglas ordenadas y precisas, se expusiere lo pertinente a ellas (LI).

89 A. GuZMÁn, "Las operaciones practicadas por Bello sobre el derecho vigente para su codificación", en Bello y la América Latina. Cuarto Congreso del Bicentenario (La Casa de Bello, Caracas, 1987)317-332.

90 F. Gómez, Instituciones..., III, 253-259; F. Gómez; V. DE la Fuente, Vicente, Lecciones..., II, 285-288; P. B. Golmayo, Instituciones..., II, 71-73; A. Manjón, Derecho..., II, 253-255; J. Donoso, Instituciones..., II, 184-186. 
Sustancialmente eran: adulterio culpable ${ }^{91}$, herejía y apostasía de la fe ${ }^{92}$, peligro espiritual ${ }^{93}$, peligro corporal ${ }^{94}$, sevicia ${ }^{95}$, cohabitación molesta ${ }^{96}$.

El código dedicó un tratamiento específico a la separación del lecho, mesa y habitación entre los cánones 1128 y 1132. Después de afirmar que "los cónyuges deben hacer en común vida conyugal, si no hay una causa justa que los excuse" (can. 1128), estableció en los cánones siguientes las causas que podrían dar lugar al divorcio perpetuo -el adulterio de uno de los cónyuges- (can. 1129-1130), y al divorcio temporal -afiliación a una secta acatólica, educación acatólica de la prole, vida criminosa e ignominiosa, peligro de alma, peligro de cuerpo, sevicias(can. 1131), sin perjuicio de que, respecto del divorcio temporal, este último canon estableciera una causal genérica complementaria - " $y$ otras cosas semejantes" - entre las que la jurisprudencia consideró, por ejemplo, el abandono malicioso ${ }^{97}$.

A la luz de la regulación codicial, bien puede decirse que la pretensión de los metropolitanos españoles se vio satisfecha toda vez que el código determinó el número y la índole de las causas que podrían dar lugar al divorcio, tanto temporal como perpetuo, pero no lo hizo taxativamente como pedían los prelados, pues, con buen criterio, dejó la posibilidad de que hubiese otras causas que aconsejaren un divorcio: la vida concreta es mucho más rica en situaciones conyugales conflictivas que las posibilidades que puedan ser previstas legislativamente. Es por lo que, aunque no se recogió expresamente "la inmoralidad manifiesta" como causa suficiente para determinar el divorcio temporal, esa posibilidad podía dar causa al divorcio temporal si, en los casos concretos en que se alegare, se consideraba de entidad suficiente como para quedar comprendida en esa genérica expresión.

\section{Algunas RefleXiones finales}

La primera constatación que es posible advertir al leer las respuestas de ambos episcopados a la consulta llegada desde Roma es la diligente

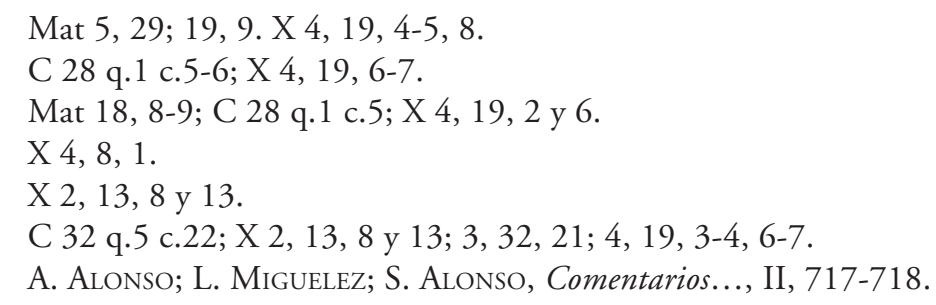


prontitud y la seriedad con que asumieron su elaboración. Prontitud, porque las mismas fueron hechas y enviadas dentro del plazo que había sido fijado desde Roma. Más aún, en el caso de los metropolitanos españoles, la diligencia les permitió enviar a Roma un texto impreso a diferencia de los prelados chilenos que solo remitieron un texto manuscrito. Seriedad, porque no fue una respuesta de ocasión, sino que las de ambos episcopados expresan un trabajo asumido con detalle, incluso con profundidad, en los que se trasluce un trabajo de equipo, en el que han trabajado expertos en las ciencias jurídicas de uno y otro fuero; en el caso de la respuesta del arzobispo de Santiago de Chile, asumida por los obispos de La Serena y Ancud, esto es evidente.

Parece claro que las propuestas que uno y otro episcopado hicieron en materia matrimonial arrancan de la experiencia pastoral cotidiana. Es, precisamente, lo que se buscaba desde Roma: poner de relieve las insuficiencias del derecho canónico vigente a efectos de introducir las reformas que parecían necesarias o, al menos, convenientes. En todos los casos, se identificaron los problemas, pero no en todos los casos se actuó de la misma manera cuando llegaba el caso de sugerir las reformas. Esta diversidad de actuación se advierte en las propuestas de ambos episcopados. En ocasiones, la reforma solo se sugiere en manera general, sin ofrecer soluciones concretas al problema, para lo cual se utilizaban expresiones genéricas como que parecía conveniente una "madura reflexión" en orden a eliminar "algunos" impedimentos o "algunos" grados de los mismos, como ocurre con los prelados chilenos; no ocurre lo mismo con los metropolitanos españoles quienes, al menos en lo que a matrimonio se refieren, fueron más específicos. En otras oportunidades, la mayoría de las veces a decir verdad, los postulata sugerían derechamente la solución.

Por lo general, las propuestas de ambos grupos de prelados se hacen directamente, sin dar mayores explicaciones que justifiquen la sugerencia que hacen. De hecho, si algo caracteriza la codificación como empresa fijadora del derecho -en uno y otro fuero- es la elaboración de textos apodícticos, es decir, que prescriben conductas, pero no dan razones del por qué se prescribe tal comportamiento; no significa esto que las normas propuestas no tengan razones que las justifiquen, solo que dichas razones no quedan consignadas en la norma, como ocurría con el derecho de las decretales. En otras ocasiones, en cambio, el postulatum es razonado y va respaldado, al menos brevemente, por las razones que lo explican. A veces, esta argumen- 
tación se hace con ocasión de una propuesta específica, como ocurre con los arzobispos españoles cuando piden la erradicación de la corruptela de los matrimonios por sorpresa. Otras veces se hace para justificar un conjunto de reformas, como ocurre con los mismos prelados hispanos con ocasión de las reformas sugeridas a diversos impedimentos dirimentes. Los prelados chilenos no fueron ajenos a este proceder, pero fueron más parcos en los razonamientos justificadores de sus propuestas.

Del total de propuestas sugeridas por uno y otro episcopado, parte importante de las mismas es coincidente, coincidencia que no excluye algunas originalidades. En efecto, solo una de las propuestas es común a ambos en toda su extensión. La mayoría de las otras propuestas que se parecen entre sí coinciden en lo sustancial, pero aportan matices que las diferencian, en aspectos menores, es cierto, pero que impiden una total semejanza. La razón de ello me parece que no hay que encontrarla en un concierto previo entre ambos episcopados -en mi opinión no tuvieron tiempo para ello habida consideración al plazo fijado por Roma y a las posibilidades de comunicación de la época- sino en que las realidades en las que se desenvolvía la Iglesia en Chile y en España eran similares en muchos aspectos. Por de pronto, el derecho cuya reforma se había iniciado era común en ambos lados del Atlántico. Pero, más importante aún, era el hecho de que las realidades culturales de una y otra iglesia no diferían sustancialmente; no en vano la cruz de Cristo había sido plantada en Chile por los españoles. Era natural, entonces, que se dieran coincidencias. Por lo demás, cuando una sociedad se enfrenta a la tarea de reformar su derecho, la libertad de los legisladores no es absoluta, por lo que es posible advertir en la evolución del derecho occidental que los pueblos que se encuentran en condiciones culturales similares, cuando se ven enfrentados a la necesidad de modificar su derecho, tienden a coincidir en sus reformas. En esto, las coincidencias que se dan entre unas y otras propuestas de los prelados chilenos y españoles se sitúan de lleno en las coordenadas de la evolución de los derechos en Occidente. Aunque el derecho canónico es el derecho de una confesión religiosa específica, es derecho y, por lo mismo, no es ajeno a la cultura de los pueblos en que la Iglesia está presente.

Sin embargo, de estas coincidencias sustanciales, los prelados chilenos se ven, en ocasiones, más avanzados en sus propuestas que los hispanos. Ello es posible advertirlo en materia de supresión de los impedimentos de afinidad ilícita y de parentesco espiritual, los que los prelados chilenos sugerían su- 
primir en su totalidad, en tanto que los españoles postulaban igualmente su supresión, pero tan solo en algunos grados.

Estas coincidencias no impidieron que uno y otro episcopado hicieran sugerencias originales, propias de cada uno de ellos. Es en ellas, quizá, donde se advierte con mayor fuerza los problemas concretos a los que se veían enfrentados en el gobierno cotidiano de sus iglesias particulares. Es lo que suceden con la pretensión chilena de que el racionalismo fuera considerado, al menos, como impedimento impediente. Y es lo que ocurre con la pretensión hispana de que se suprimiere la corruptela del matrimonio por sorpresa, algo que en Chile no ofrecía mayor problema, a diferencia de lo que ocurría en España; la sola incorporación de esta propuesta es reveladora en este sentido, toda vez que la proposición no es la de un obispo en particular, sino de todos los metropolitanos españoles.

Una mirada global sobre los postulata que arribaron a Roma desde Chile y España nos muestra a unos obispos comprometidos con la Iglesia de su tiempo, preocupados de sus problemas e interesados en colaborar con la Santa Sede en la ingente labor de sustituir el viejo derecho de las decretales por un derecho acorde con los nuevos tiempos cuya reforma, como decían los metropolitanos peninsulares al inicio de su informe, era "deseada en grado sumo por obispos, concilios, doctores y varones muy distinguidos". La falta de preparación canónica que pudieron haber tenido algunos de ellos, se vio suplida por la preparación de los colaboradores a quienes acudieron para preparar la respuesta. En el caso de los obispos de la provincia chilena eso es evidente. En la respuesta española no hace alusión a una comisión similar, pero no es aventurado pensar en que los metropolitanos contaron con el auxilio de expertos.

El resultado de estas propuestas fue dispar. Algunas de ellas simplemente no fueron consideradas, como ocurrió con la sugerencia chilena de establecer el racionalismo como impedimento impediente. Otras fueron derechamente acogidas. No significa esto que las específicas sugerencias chilenas o españolas en materia matrimonial fueran el origen de algún canon de los que regularon el matrimonio en el Codex, sino que las intuiciones de estos prelados estaban en consonancia con las de los propios codificadores y, en no pocos casos, con las de otros episcopados. No faltaron casos en los que las propuestas no fueron acogidas en la forma sugerida, pero las inquietudes episcopales quedaron igualmente satisfechas en cánones que, formulados en términos más generales, daban cumplida respuesta a sus preocupaciones. 
Según viejo brocardo medieval "ubi societas ibi ius". Nadie puede negar el carácter societario de la Iglesia Católica y, por lo mismo, a lo largo de los siglos ha ido desarrollando un derecho propio con total independencia de los poderes seculares. Pero la Iglesia -y su derecho- están inmersos en la historia de los hombres y, por lo mismo, sujeta a los avatares de la misma historia, por lo que su derecho tiene que estar constantemente sujeto a revisión para, haciéndose eco de los signos de los tiempos, dejar de lado instituciones que ya han cumplido su ciclo histórico, para acomodarlas a las nuevas realidades o, más radicalmente, para dar nacimiento a nuevas categorías jurídicas. Esta vitalidad de la Iglesia y de su derecho aparece con particular evidencia en los postulata de los prelados chilenos y españoles: sus propuestas se hicieron tomando el pulso al momento histórico en que se encontraban. Se trataba no solo de presentar el derecho canónico con un nuevo ropaje externo, el de la codificación ius-racionalista, sino que se trataba de introducirlo -consciente o inconscientemente- en una etapa nueva de la historia. Había, pues que dejar lado, por ejemplo, al matrimonio por sorpresa o el impedimento de parentesco espiritual; había que modificar los impedimentos de consanguinidad y afinidad; y había que abrir nuevas pistas para el actuar de los párrocos en la dispensa de algunos impedimentos matrimoniales.

Pero la Iglesia no solo está inmersa en el tiempo de los hombres, sino que, por su propia vocación, está llamada a estar en medio de todos ellos, en cumplimiento del mandato de su maestro de "ir y hacer discípulos a todas las gentes" (Mt 28, 19). La universalidad que es connatural a la Iglesia, sin embargo, ha de tomar en cuenta las realidades particulares en las que la Iglesia realiza su actuar, por lo que la existencia de un derecho universal no niega la de un derecho particular $y$ ha de dejar espacio a las peculiaridades regionales, las que, además, ayudan a configurarlo. Por ello, es posible advertir, tanto en los postulata chilenos como españoles, que la inspiración de algunos de ellos arranca de las realidades particulares que estaban experimentando los prelados: las particularidades alimentan la universalidad, en una tensión que es propia del derecho canónico y que constituye parte de su riqueza.

En suma, la participación chilena en estos primeros momentos de la codificación canónica no desmereció en nada frente a la de los metropolitanos peninsulares, mostrando, así, la calidad intelectual de los prelados que tenían en sus manos la no siempre fácil tarea de hacer que el Pueblo de Dios peregrinante en Chile y en España "tenga vida y la tenga en abundancia" (Jn $10,10)$. 